\title{
Desain Modifikasi Struktur Gedung Pusat Peelitian dan Pendidikan Dokter Gigi Universitas Brawijaya Malang dengan Penambahan Lantai Menggunakan Sistem Rangka Bresing Eksentris
}

\author{
Heppy Kristijanto, Tavio dan Ahmad Fatihuddin Afif \\ Departemen Teknik Sipil, Fakultas Teknik Sipil dan Perencanaan, Institut Teknologi Sepuluh Nopember (ITS) \\ e-mail: tavio@ce.its.ac.id
}

\begin{abstract}
Abstrak - Pada awalnya gedung Dental Nano Material Pusat Penelitian dan Pendidikan Dokter Gigi Universitas Brawijaya ini merupakan gedung 10 lantai yang menggunakan konstruksi beton bertulang dengan luas bangunan $60,2 \mathrm{~m} \times 60 \mathrm{~m}$, dimana luas bangunan sama per lantainya. Sebagai bahan perencanaan ini, akan dilakukan modifikasi penambahan lantai keatas pada struktur gedung Dental Nano Material Pusat Penelitian dan Pendidikan Dokter Gigi Universitas Brawijaya menggunakan Sistem Rangka Bresing Eksentris. Modifikasi desain yang akan dilakukan adalah expansi lantai gedung dengan menggunakan struktur baja. Dari analisa dan hasil perhitungan diperoleh hasil, yaitu tebal pelat bondeks 9 cm, dimensi balok induk WF 600 x 300 x 12 x 20, balok link WF $600 \times 300 \times 12 \times 20$, dimensi bresing WF $350 \times 350 \times 12 \times$ 19, dimensi kolom WF $400 \times 400 \times 20 \times 35$, dan panjang elemen link direncanakan $100 \mathrm{~cm}$. Kondisi eksisting masih mampu menahan expansi 5 lantai keatas.
\end{abstract}

Kata Kunci-Gempa, Sistem Rangka Bresing Eksentris, Penambahan Lantai, Beton Bertulang, Struktur Baja.

\section{PENDAHULUAN}

ALAH satu hal yang perlu diperhatikan dalam $\checkmark$ pembangunan gedung bertingkat tinggi adalah gempa. Syarat dalam merencanakan bangunan tahan gempa adalah stabil, kuat, dan kaku antar sambungannya. Pada dasarnya beban gempa adalah beban lateral yang bersifat bolak-balik sehingga struktur harus diberi pengaku untuk menahannya. Pada struktur baja umumnya digunakan pengaku yang disebut juga bresing [1].

Pada awalnya gedung Dental Nano Material Pusat Penelitian dan Pendidikan Dokter Gigi Universitas Brawijaya ini merupakan gedung 10 lantai yang menggunakan konstruksi beton bertulang dengan luas bangunan $60,2 \mathrm{~m}$ x $60 \mathrm{~m}$, dimana luas bangunan sama per lantainya. Semakin bertambahnya tahun, semakin banyak pula peminat yang masuk ke pendidikan dokter gigi di Universitas Brawijaya. Dan tentunya pada gedung ini membutuhkan penambahan ruangan untuk mahasiswa, serta material dan alatnya. Akan tetapi pada gedung ini terdapat keterbatasan lahan, sehingga sulit untuk memperluas struktur untuk penambahan ruangan.

Dilihat dari kondisi tersebut, maka dari itu perlu penambahan lantai keatas dengan menggunakan konstruksi baja. Dan juga mempertahankan kondisi pada struktur yang sudah ada agar tidak merubah strukturnya dan dapat menampung dari beberapa kondisi pada konstruksi baja tersebut.

Artikel ini akan membahas desain modifikasi penambahan lantai keatas pada struktur gedung Dental Nano Material Pusat Penelitian dan Pendidikan Dokter Gigi Universitas Brawijaya menggunakan Sistem Rangka Bresing Eksentris (SRBE). Hal ini dilakukan karena pada SRBE memiliki kelebihan dibandingkan Struktur Rangka Pemikul Momen (SRPM) maupun Sistem Rangka Bresing Konsentrik (SRBK). SRBE memiliki kekakuan yang lebih tinggi dibandingkan SRPM, dan memiliki daktilitas yang lebih tinggi dibandingkan SRBK [2].

Konsep desain SRBE adalah link ditetapkan sebagai bagian yang akan rusak, sedangkan elemen lain tetap berada dalam kondisi elastik. Kelelehan yang terjadi pada elemen link dapat berupa kelelehan geser/kelelehan lentur [3].

\section{METODE STUDI}

\section{A. Sistem Rangka Bresing Eksentris (SRBE)}

Sistem Rangka Bresing Eksentris (SRBE) adalah suatu sistem rangka baja yang terdiri dari balok, kolom, dan pengaku dimana pada ujung dari bagian pengakunya terdapat suatu elemen yang menggabungkan antar bagian dari sistem rangka yang disebut link. Elemen ini sangat penting dalam desain SRBE yang diharapkan sebagai elemen yang menyerap energi gempa dengan proses plastifikasi. Pada elemen yang rusak tersebut digunakan sebagai sarana pemencaran energi, hal ini dikarenakan area plastis tersebut memiliki rentang regangan energi yang begitu besar untuk bisa dimanfaatkan [2].
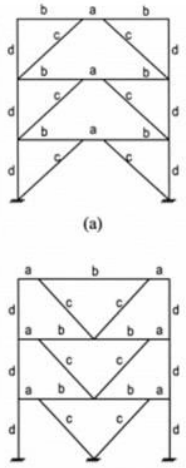

(c)

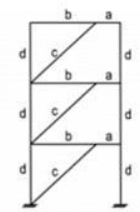

(b)

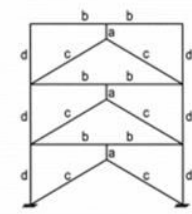

$a=$ Link

$\mathrm{b}=$ beam segment outside of $\mathrm{Link}$

Gambar 1. Beberapa contoh konfigurasi SRBE [4] 
Sistem Rangka Bresing Eksentrik (SRBE) adalah kombinasi gabungan dari Sistem Rangka Pemikul Momen (SRPM) yang sangat daktail dan Sistem Rangka Bresing Konsentrik (SRBK) yang memiliki kekakuan dan kekuatan yang cukup baik. Pada Gambar 2 dijelaskan tentang kurva hubungan antara gaya lateral dengan perpindahan yang terjadi pada SRBK, SRBE, dan SRPM. SRBE dapat memberikan perilaku struktur yang di harapkan saat terjadi gempa yaitu cukup kaku seperti halnya SRBK tetepi juga tidak terlalu memiliki deformasi yang besar seperti SRPM

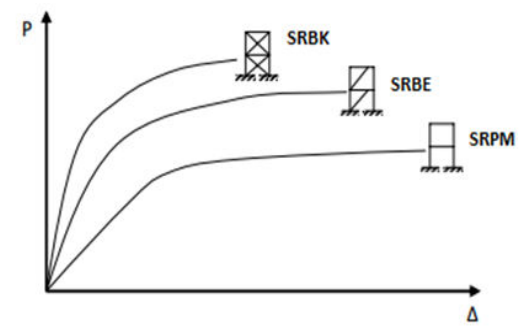

Gambar 2. Perbedaan perilaku tiga model sistem rangka baja [2]

\section{B. Mekanisme Energy Disipasi SRBE}

Pada design struktur penahan gempa dengan SRBE perlu diperhitungkan besar rotasi plastis yang akan dialami oleh link. Pada tahap ini lebih mudah menggunakan mekanisme disipasi energi (juga disebut mekanisme kehancuran) (Engelheardt 2007). Gambar 3. menunjukkan mekanisme kehancuran dari SRBE. Pada setiap kasus $\theta$ merupakan besar penyimpangan yang terjadi pada rangka, besar penyimpangan pada sendi plastis terhadap balok juga disimbolkan $\theta$. Untuk SRBE besar dari kebutuhan rotasi link $(\gamma)$ harus lebih besar dari $\theta$.

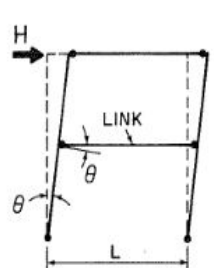

(a)

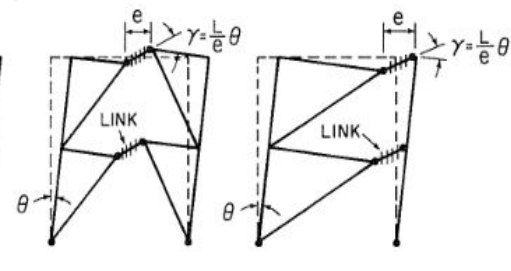

(b)

(c)
Gambar 3. Mekanisme energy disipasi[3]

\section{ANALISIS DAN PEMBAHASAN}

\section{A. Bangunan yang ditinjau}

Pada perencanaan ini bangunan ditinjau adalah Gedung Pusat Penelitian Dan Pendidikan Dokter Gigi Universitas Brawijaya Malang. Bangunan dimodifikasi menjadi 15 lantai dengan ketinggian 59,35 m.

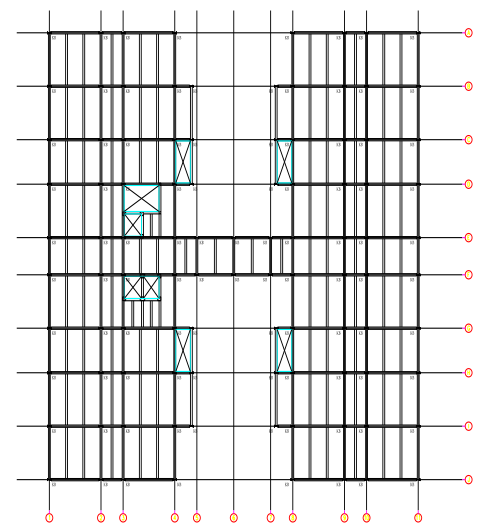

Gambar 4. Denah Gedung Struktur.
Fungsi Bangunan

Faktor Keutamaan $\left(\mathrm{I}_{\mathrm{e}}\right)$

Mutu Baja

Mutu Beton

Lebar Gedung

Panjang Gedung

Tinggi Total Gedung

Tinggi Antar Lantai

Pelat Lantai Atap

Pelat Lantai

Profil Kolom

Profil Balok

Profil Bresing

\section{B. Analisa Struktur}

Pemodelan struktur pada gedung ini adalah penambahan lantai menggunakan Sistem Rangka Bresing Eksentrik (SRBE). Struktur rangka bresing eksentrik berfungsi sebagai penahan gaya lateral yang terjadi akibat gempa. Struktur yang direncanakan adalah bangunan yang terdiri dari 14 lantai dan 1 lantai atap dengan total tinggi struktur 59,35 meter.

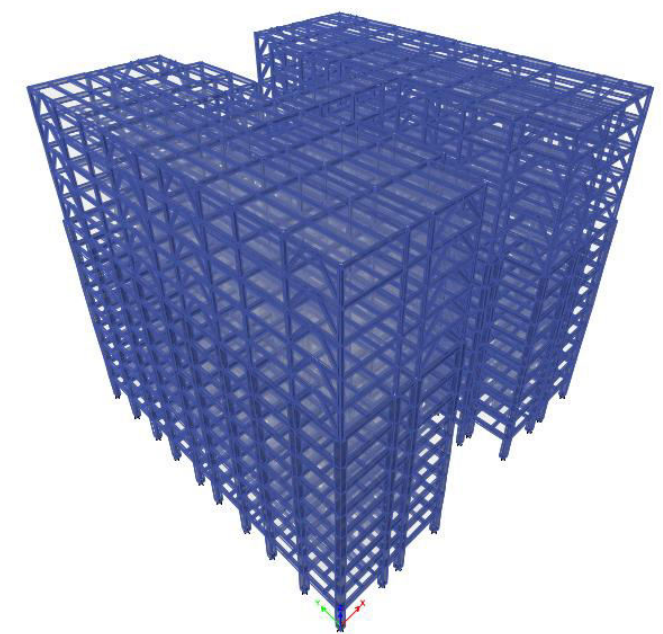

Gambar 5. Pemodelan Struktur 3 Dimensi

Hasil analisa struktur perlu dikontrol sesuai syarat yang berlaku. Hal tersebut dilakukan untuk meninjau kelayakan struktur dalam memikul beban yang bekerja. Berikut ini adalah kontrol-kontrol yang dilakukan terhadap hasil analisa struktur:

\section{Kontrol Penerimaan Pemodelan}

Untuk membuktikan hasil pemodelan struktur sesuai dengan kenyataan aslinya, perlu dilakukan pengecekan dengan perhitungan manual, dengan meninjau satu kolom, dengan kombinasi $\mathrm{D}+\mathrm{L}$, hasil dari analisa program bantu ETABS 2013 harus sesuai dengan perhitungan manual dengan batasan perbedaan $5 \%$, dari hasil perhitungan didapat perbedaan sebesar $3 \%$ maka pemodelan dapat di terima

\section{Kontrol Partisipasi Massa}

Perhitungan respon dinamik struktur harus sedemikian rupa sehingga partisipasi massa ragam terkombinasi paling sedikit sebesar $90 \%$ dari massa aktual dari masingmasing arah. Dari analisa program bantu ETABS 2013 didapat partisipasi massa arah X sebesar 92,96\% pada moda ke 7 dan partisipasi massa arah Y sebesar 90,1\% pada moda ke 5 . 


\section{Kontrol Waktu Getar Alami Fundamental}

Untuk mencegah pengunaan struktur gedung yang terlalu fleksibel, nilai waktu getar alami fundamental (T) dari struktur gedung harus dibatasi. Dari hasil analisi didapat T = 1,979 s. Maka berdasarkan kontrol waktu getar alami fundamental nilai $\mathrm{T}$ lebih besar dari $\mathrm{C}_{\mathrm{u}} \times \mathrm{T}$. Jadi analisis struktur gedung Dental UB Malang menggunakan nilai $\mathrm{T}$ output program bantu ETABS 2013 yaitu $\mathrm{T}=1,979 \mathrm{~s}$ dengan nilai akhir respon spektrum dan batas simpangan antar lantai harus memenuhi syarat.

\section{Kontrol Nilai Akhir Respon Spektrum}

Dari hasil analisis menggunakan program bantu ETABS 2013 didapatkan nilai gaya geser dasar (base shear) yang disajikan pada Tabel 1.

Tabel 1.

Gaya Geser Dasar Akibat Beban Gempa

\begin{tabular}{ccc}
\hline \hline OutputCase & GlobalFX & GlobalFY \\
\hline Text & Kgf & Kgf \\
Quake X & 1361616,33 & 395034 \\
Quake Y & 408476,76 & 1316805,98 \\
\hline \hline
\end{tabular}

Kontrol :

- Untuk gempa arah X :

$\mathrm{V}_{\text {dinamik }}>85 \%$. $\mathrm{V}_{\text {statik }}$

$1361616,33 \mathrm{~kg}>85 \% .1947310,455 \mathrm{~kg}$

$1361616,33 \mathrm{~kg}>1655213,887 \mathrm{~kg}$ (Not OK...!)

- Untuk gempa arah Y :

$\mathrm{V}_{\text {dinamik }}>85 \%$. $\mathrm{V}_{\text {statik }}$

$1316805,98 \mathrm{~kg}>85 \% .1947310,455 \mathrm{~kg}$

$1316805,98 \mathrm{~kg}>1655213,887 \mathrm{~kg}$ (Not OK...!)

maka harus diperbesar dengan faktor skala $0,85 \cdot \frac{C s \cdot W}{V}$.

Untuk arah $\mathrm{X}$ dikali dengan $\mathrm{SF}=1,737$

Untuk arah Y dikali dengan $\mathrm{SF}=1,08$

5. Kontrol Batas Simpangan Antar Lantai

Pembatasan simpangan antar lantai suatu struktur bertujuan untuk mencegah kerusakan non-struktur dan ketidaknyamanan penghuni.

\section{Struktur Primer dan SRBE}

1. Link

Balok link didapatkan menggunakan profil WF 600 x 300 x 12 x 20. Hasil dari output program bantu ETABS 2013 diperoleh hasil perhitungan:

$$
\begin{aligned}
& \mathrm{e}=100 \mathrm{~cm} \quad<1,6 . \mathrm{Mp} / \mathrm{Vp}=174,73 \mathrm{~cm} \\
& \alpha=0,01 \text { radian }<\alpha \text { maks }=0,08 \text { radian } \\
& \mathrm{Nu}=36,2 \mathrm{~kg} \quad<0,15 \mathrm{Ny}=72187,5 \mathrm{~kg} \\
& \mathrm{Vu}=63641,08 \mathrm{~kg}<\varnothing \mathrm{Vn}=88776 \mathrm{~kg}
\end{aligned}
$$

Untuk pengaku dengan panjang link $<1,6 . \mathrm{Mp} / \mathrm{Vp}$, harus direncanakan memiliki pengaku antara. Untuk $\alpha=$ 0,04 radian maka dipasang pengaku antara dengan jarak $25 \mathrm{~cm}$.

2. Balok Diluar Link

Balok link didapatkan menggunakan profil WF 600 x 300 x 12 x 20. uat perlu balok yang terletak diluar link harus ditentukan berdasarkan gaya- gaya yang ditimbulkan paling tidak 1,1 kali kuat geser nominal link sebesar Ry.Vn [5]. Kontrol interaksi geser lentur yang terjadi:

$$
\begin{gathered}
\frac{M u}{\phi M n}+0,625 \frac{V u}{\phi V n} \leq 1,375 \\
1,03 \leq 1,375(\mathrm{OK})
\end{gathered}
$$

\section{Bresing}

Bresing didapatkan menggunakan WF 350 x 350 x 12 x 19, Kuat kombinasi aksial pada batang bresing harus sebesar 1,25 Ry Vn.

$$
\begin{aligned}
\mathrm{Vu} & =1,25 \cdot \mathrm{Ry} \cdot \mathrm{Vn} \\
& =1,25 \cdot 1,5 \cdot 56160 \\
& =105300 \mathrm{~kg}
\end{aligned}
$$$$
P_{u} \text { tekan }=P_{u} \text { tarik }=\frac{V_{u}}{\sin \alpha}=\frac{105300}{\sin 48,62^{0}}
$$

Bresing tarik

$$
=140332,8 \mathrm{~kg}
$$

$$
\begin{aligned}
& \begin{aligned}
\phi_{c} P_{n} & =0,9 \cdot R_{y} \cdot F_{y} \cdot A g \\
& =0,9 \cdot 1,5 \cdot 2500 \cdot 173,9=586912,5 \mathrm{~kg}
\end{aligned} \\
& \begin{aligned}
\phi_{c} P_{n} & >P u \rightarrow 586912,5 \mathrm{~kg}>140332,8 \mathrm{~kg}(\mathrm{OK})
\end{aligned} \\
& \text { Bresing tekan } \\
& \begin{aligned}
\phi_{c} P_{n} & =0,85 \cdot 1,1 \cdot R_{y} \cdot A g \cdot F_{c r} \\
& =0,85 \cdot 1,1 \cdot 1,5 \cdot 173,9 \cdot 2021,35 \\
& =492995,8 \mathrm{~kg}
\end{aligned} \\
& \begin{aligned}
\phi_{c} P_{n} & >P u \rightarrow 492995,8 \mathrm{~kg}>140332,8 \mathrm{~kg}(O K)
\end{aligned} \\
& \text { 4. Balok }
\end{aligned}
$$

Balok didapatkan menggunakan profil WF $600 \times 300 \times 12$ $\times$ 20. Dari output ETABS 2013 diperoleh gaya dalam yang dipakai dalam desain adalah:

$$
\begin{array}{rlrl}
\mathrm{Mu} & =72056,25 \mathrm{~kg} \cdot \mathrm{m} & <\varnothing \mathrm{Mn}=96950,52 \mathrm{~kg} \cdot \mathrm{m} \\
\mathrm{Vu} & =33415,41 \mathrm{~kg} & \leq \varnothing \mathrm{Vn}=95256 \mathrm{~kg} \\
\mathrm{f} 0 \quad=0,095 \mathrm{~cm} & \leq \text { fijin }=1,39 \mathrm{~cm}
\end{array}
$$

5. Kolom

Kolom didapatkan menggunakan WF 400 x 400 x 20 x 35 dengan kontrol kuat nominal penampang:

Rumus Interaksi:

$\frac{P u}{\varphi P n}=0,205>0,2$

Kontrol Interaksi "Balok - Kolom"

$\frac{P_{u}}{\emptyset P_{n}} \geq 0,2 \rightarrow \frac{P_{r}}{\emptyset P_{c}}+\frac{8}{9}\left(\frac{M_{r x}}{M_{c x}}+\frac{M_{r y}}{M_{c y}}\right) \leq 1,0$

$0,23 \leq 1,0(\mathrm{OK})$

\section{Sambungan Antar Kolom}

Sambungan kolom dengan kolom direncanakan pada lantai 2 pada menggunakan sambungan baut. Sambungan ditempatkan pada posisi tengah dari ketinggian lantai seperti pada Gambar 6. 


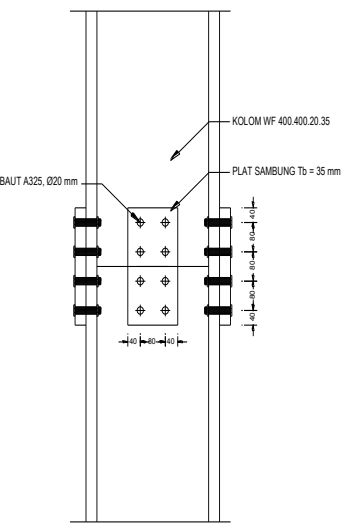

Gambar 6. Sambungan Antar Kolom

6. Sambungan Balok Induk Dengan Kolom

Sambungan menghubungkan balok profil WF $600 \times 300 \times$ $12 \times 20$ dengan kolom WF $400 \times 400 \times 20 \times 35$ disajikan pada Gambar 7 .

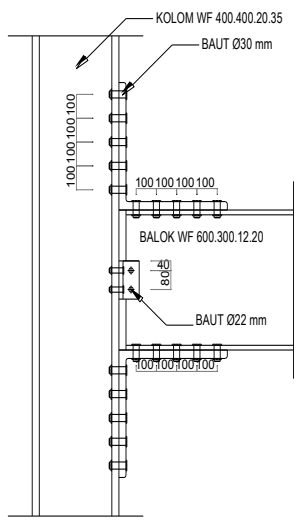

Gambar 7. Sambungan Balok dengan Kolom

7. Sambungan Batang Bresing

Sambungan bresing direncanakan menggunakan plat dengan tebal $19 \mathrm{~mm}$ dengan las sudut dengan a $=6 \mathrm{~mm}$ disajikan pada Gambar 8 dan Gambar 9.

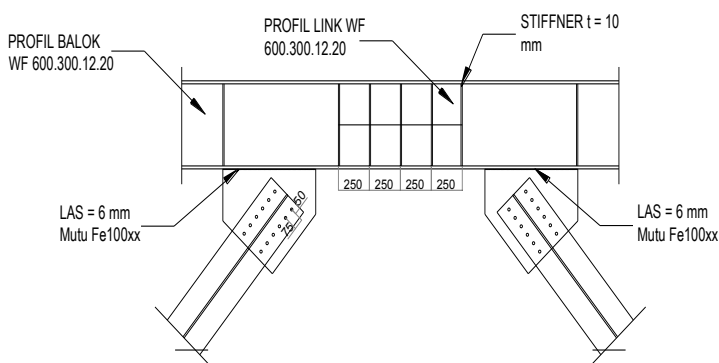

Gambar 8. Sambungan Bresing dengan Balok Link

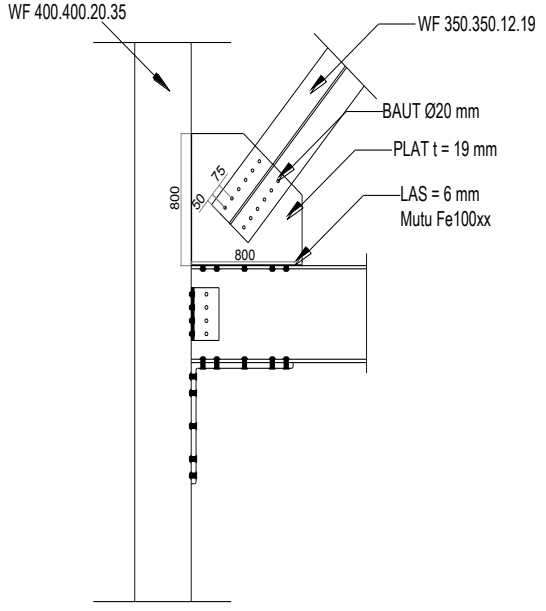

Gambar 9. Sambungan Bresing dengan Balok dan Kolom

8. Sambungan Baseplate

Dari hasil analisis ETABS 2013 didapat gaya yang bekerja pada kolom WF 400 × 400 × 20 x 35 paling bawah:

$\mathrm{Pu}=256922,5 \mathrm{~kg}$

$\mathrm{Mu}=11638,65 \mathrm{kgm}$

$\mathrm{Vu}=6378,11 \mathrm{~kg}$

- Cek eksentrisitas gaya

$e=\frac{M_{u}}{P_{u}}=\frac{11638,65}{256922,5}=0,05 \mathrm{~cm}<12,49 \mathrm{~cm}$

Termasuk dalam kategori baseplate yang memikul gaya aksial, gaya geser dan juga momen lentur dengan intensitas yang cukup kecil, sehingga distribusi tegangan tidak terjadi sepanjang baseplate, namun momen lentur yang bekerja masih belum mengakibatkan baseplate terangkat dari beton penumpu. Angkur terpasang hanya berfungsi sebagai penahan gaya geser, disamping itu angkur tersebut juga berfungsi menjaga stabilitas struktur selama masa konstruksi

Didapatkan menggunakan angkur berdiameter $16 \mathrm{~mm}$

\section{Kontrol Penampang Eksisting}

\section{$\checkmark$ Balok}

Penampang masih bisa memikul beban-beban yang bekerja pada expansi lantai. Diambil salah satu contoh penampang yang disajikan pada Gambar 10.

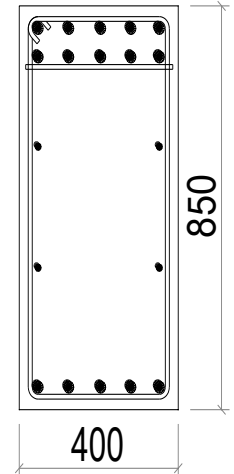

Gambar 10. Penampang balok eksisting

Dari hasil output program bantu ETABS 2013, didapatkan gaya dalam sebagai berikut:

$\mathrm{M}_{\mathrm{u}}=582077600 \mathrm{Nmm}$ (tumpuan-tarik)

$\mathrm{M}_{\mathrm{u}} \quad=63180029,09 \mathrm{Nmm}$ (tumpuan-tekan) 
$\mathrm{M}_{\mathrm{u}} \quad=217248600 \mathrm{Nmm}$ (lapangan-tarik)

$\mathrm{M}_{\mathrm{u}}<\varnothing \mathrm{M}_{\mathrm{n}}$

○ Tumpuan-tarik $582077600<952112634,6 \mathrm{Nmm}$

$0,611<1 \ldots$ OK!

○ Tumpuan-tekan $63180029,09<500316920,1 \mathrm{Nmm}$

$0,126<1 \ldots$ OK!

- Lapangan-tarik

$217248600<952112634,6 \mathrm{Nmm}$

$0,228<1 \ldots$ OK!

\section{Kolom}

Penampang masih bisa memikul beban-beban yang bekerja pada expansi lantai. Diambil salah satu contoh penampang yang disajikan pada Gambar 11 .

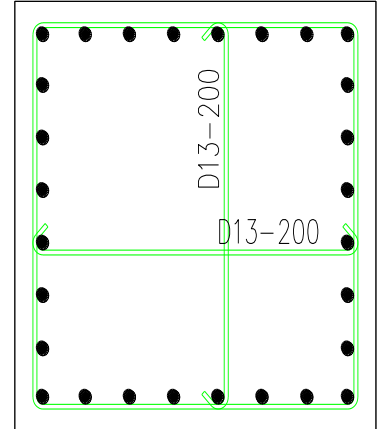

Gambar 11. Penampang kolom eksisting

Didapatkan hasil output program bantu ETABS 2013 adalah sebagai berikut:
$\mathrm{Pu}_{1}=7961,4 \mathrm{kN}$
$\mathrm{Mnx}_{1}=693,3 \mathrm{kN} \cdot \mathrm{m}$
$\mathrm{Pu}_{2}=6882,7 \mathrm{kN}$
$\mathrm{Mnx}_{2}=709,9 \mathrm{kN} . \mathrm{m}$
$\mathrm{Pu}_{3}=2392,4 \mathrm{kN}$
$\mathrm{Mnx}_{3}=685,2 \mathrm{kN} . \mathrm{m}$

Momen kapasitas yang dihasilkan dari program bantu

PCACol adalah sebagai berikut:

$\varnothing \mathrm{Mnx}_{1}=2247,7 \mathrm{kN} . \mathrm{m}$

$\varnothing \mathrm{Mnx}_{2} \quad=2362,9 \mathrm{kN} . \mathrm{m}$

$\varnothing \mathrm{Mnx}_{3}=2578,5 \mathrm{kN} . \mathrm{m}$

\section{$\checkmark$ Desain Tiang Pancang}

Penampang masih bisa memikul beban-beban yang bekerja pada expansi lantai. Diambil salah satu contoh yang disajikan pada Gambar 12.

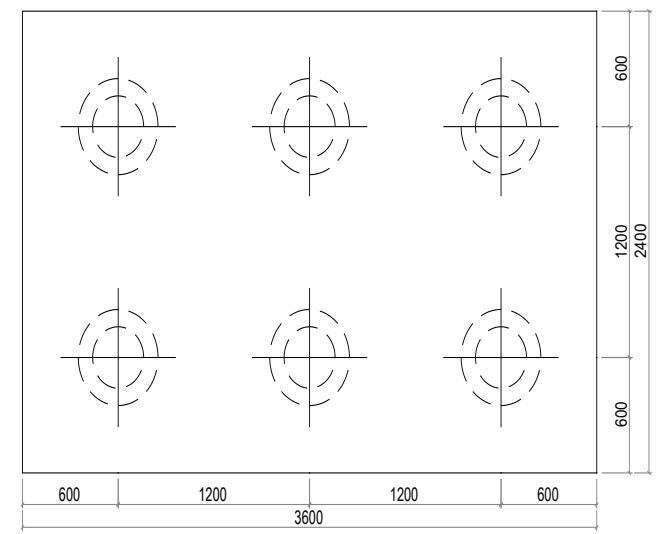

Gambar 12. Pondasi Tiang Pancang
Besarnya gaya - gaya dalam kolom diperoleh dari hasil analisis ETABS 2013 pada pada kolom lantai 1, adalah

$\mathrm{Pu}=4724 \mathrm{kN}$

$\mathrm{Mu}=649,79 \mathrm{kN} \cdot \mathrm{m}$

Jumlah pancang yang dibutuhkan :

$$
\begin{aligned}
\mathrm{n} & =\frac{\sum \mathrm{P}}{\overline{\mathrm{P}}} \\
& =\frac{493,137}{152}=3,24 \approx 6 \text { buah }
\end{aligned}
$$

Seluruh penampang eksisting masih mampu menahan beban setelah expansi lantai.

\section{PENUTUP}

Kesimpulan yang dapat diambil yaitu sebagai berikut:

1. Hasil analisa struktur sekunder telah memenuhi syarat.

2. Hasil analisa struktur primer telah memenuhi syarat.

3. Hasil analisa struktur bresing \& link telah memenuhi syarat.

4. Hasil permodelan struktur telah memenuhi syarat.

5. Perencanaan sambungan telah memenuhi syarat.

6. Penampang eksisting masih bisa menahan beban-beban setelah adanya expansi lantai 5 lantai

7. Hasil dari perencanaan struktur dapat dilihat pada lampiran gambar berupa gambar teknik.

Diharapkan dilakukan studi lebih lanjut yang mempelajari tentang perencanaan struktur Sistem Rangka Bresing Eksentris dan penambahan lantai keatas lebih dalam dengan mempertimbangkan aspek teknis, ekonomis, dan estetika.

\section{DAFTAR PUSTAKA}

A. E. Putra and D. Iranata, "Modifikasi Perencanaan Struktur Gedung Apartemen Puncak Kertajaya Menggunakan Struktur Baja Dengan Sistem Ganda Pada Wilayah Gempa Kuat," J. Tek. POMITS, pp. 1-6, 2014.

[2] Yurisman, B. Budiono, M. Moestopo, and M. Suarjana, "Kajian Numerik Terhadap Kinerja Link Geser dengan Pengaku Diagonal pada Struktur Baja Berpenopang Eksentrik (EBF)," J. Tek. Sipil, pp. 25-38, 2010.

[3] E. P. Popov and M. D. Engelhardt, "Seismic Eccentrically Braced Frames," J. Constr. Steel Res., vol. 10, pp. 321-354, 1988.

[4] ANSI/AISC 341-10, "Seismic Provisions for Structural Steel Buildings," 2010.

[5] Badan Standarisasi Nasional, "SNI 03-1729-2002 Tata Cara Perencanaan Struktur Baja Untuk Bangunan Gedung," Jakarta, 2002. 